\title{
Pengurusan Daya Intelek Kanak-Kanak Melalui Rangsangan Imaginasi dalam Episod Cari dan Simpan Berdasarkan Prinsip Kepimpinan
}

\author{
${ }^{1}$ Norsaliza Mohd Shuhaini, ${ }^{2}$ Azhar Wahid \\ ${ }^{1}$ Institut Peradaban Melayu, Universiti Pendidikan Sultan Idris, Tanjong Malim, Perak, \\ ${ }^{2}$ Fakulti Bahasa dan Komunikasi, Universiti Pendidikan Sultan Idris, Tanjong Malim, Perak \\ ${ }^{1}$ saliza@pbmpu.upsi.edu.my, ${ }^{2}$ azhar@fbk.upsi.edu.my
}

Received: 02 October 2020; Accepted: 29 December 2020; Published: 30 December 2020

To cite this article (APA): Mohd Shuhaini, N., \& Wahid, A. (2020). Pengurusan Daya Intelek Kanak-Kanak Melalui Rangsangan Imaginasi dalam Episod Cari dan Simpan Berdasarkan Prinsip Kepimpinan. Jurnal Peradaban Melayu, 15, 38-52. https://doi.org/10.37134/peradaban.vol15.4.2020

To link to this article: https://doi.org/10.37134/peradaban.vol15.4.2020

\begin{abstract}
ABSTRAK
Alam pembelajaran kanak-kanak bermula dengan tercetusnya satu pengalaman. Membesar dalam kemajuan pembangunan teknologi dan perisian evolusi abad ke 21 mencabar proses perkembangan intelek kanak-kanak. Intelligent Quotient (IQ), iaitu kecerdasan akal semata-mata tidak menjanjikan keseimbangan dan kejayaan dalam pengurusan kehidupan Kekaguman dan ketinggian intelek yang terkandung di dalamnya mempamerkan kerelevanan dalam upayanya mengendalikan daya intelek dan imaginasi kanak-kanak. Terdahulu, kanak-kanak leka dengan sastera lisannya tetapi gaya hidup kini mengubah kehidupan semula jadi kanak-kanak melalui ledakan informasi pembangunan teknologi yang berupaya mempengaruhi minda kanak-kanak dengan maklumat kurang tepat dan mengelirukan. Dengan menggunakan bahan tontonan kartun animasi Upin dan Ipin, objektif kajian ini dijalankan adalah untuk menganalisis bagaimana kanak-kanak menguruskan daya intelek dalam episod "Cari dan Simpan". Kajian ini dijalankan dengan menggunakan Prinsip Kepimpinan yang terkandung dalam Pendekatan Pengurusan (Mohammad Mokhtar Abu Hassan, 2013). Pemaparan episod Upin dan Ipin ini memperlihatkan pengurusan daya intelek dan rangsangan imaginasi kanak-kanak dalam menguruskan kehidupan tanpa sengaja, tiada paksaan dan tiada kekasaran yang hanya akan menghentikan proses pembelajaran kanak-kanak. Hasil daripada kajian ini menjelaskan dalam proses kanak-kanak mencari logik, mereka banyak menggunakan daya intelek dan rangsangan imaginasi bagi membentuk realiti dalam kehidupan dengan memikirkan cara menyelesaikan masalah yang dihadapi. Selain itu, dapatan kajian ini juga dapat memberikan sumbangan dari segi penambahan kajian-kajian berkaitan dengan pengurusan kehidupan kanak-kanak.
\end{abstract}

Kata kunci: daya, intelek, imaginasi, animasi, Prinsip Kepimpinan, kanak-kanak

\begin{abstract}
Children's learning environment begins with an experience. Growing up in the advancement of technology and software development in the 21st century challenges the process of children's intellectual development. Previously, children were immersed in verbal literature but then the current lifestyle has changed their lives through the development of information technology explosion which can influence their minds with inaccurate and misleading information. By using an animated cartoon entitled 'Upin dan Ipin', this study aims to analyse how well the children are managing their intellectual and imagination abilities in the episode of 'Cari dan Simpan'. This study has been conducted by using the Management Approach (Mohammad Mokhtar Abu Hassan, 2013), based on the Education Dimensions contained in the Leadership Principles. This particular episode of 'Upin dan Ipin' has shown the management of the children's intellectual and imagination abilities in managing their lives without coercion and rudeness. Rudeness or violence will only put an end to the learning process of the children. The findings of this study explain that children use a lot of intellectual and imagination abilities to form the reality of life, especially in the
\end{abstract}


process of logic seeking with children's brain to figure out how to solve the problem faced. Other than that, the findings of this study also contribute to other studies related to life management of children.

Keywords: Intellect, imagination, animation, leadership principles, children

\section{PENGENALAN}

Penontonan berupaya mempengaruhi perkembangan pemikiran kanak-kanak. Industri kreatif tempatan mensasarkan kanak-kanak yang membesar dalam dunia teknologi tanpa kawalan mutlak ibu bapa sebagai penonton setia. Skop animasi kartun yang bukan sahaja tertumpu kepada pembikinan yang mengujakan, bahkan diperkembang dan diaplikasi bukan sekadar menghiburkan tetapi turut mengeksploitasi refleksi peristiwa, dan penataran watak berdasarkan penggunaan imaginasi alam nyata berdasarkan paparan alam maya. Melalui penontonan kartun ketajaman intelek dan rangsangan imaginasi kanak-kanak digilap melalui keupayaan kepimpinan watak dewasa dalam membimbing kanak-kanak melalui bimbingan dan cetusan peristiwa sebelum atau selepas penontonan berlaku.

Catatan kajian terbaru Mead Johnson Nutrition dalam Yusliza Yakimir Abd.Talib (2011) mendapati penentuan masa akan datang yang tidak menentu menunjukkan 96 peratus ibu-ibu di Malaysia mendapati $I Q$ sahaja tidak memadai untuk anak-anak berjaya. Kanak-kanak perlu berupaya menggunakan $I Q$ untuk disesuaikan dalam apa juga keadaan, kebolehan dalam berempati, berkemahiran dalam bersosial dan berkomunikasi dengan baik lebih-lebih lagi menjengah pengurusan hidup kanak-kanak abad ke-21. Hal ini demikian kerana setiap kanak-kanak mempunyai keupayaan yang berbeza dalam mengawal pemikiran kendirinya. Malahan, hujah membuktikan cara pemikiran dan tindakan kanak-kanak yang terbimbing tidak boleh diukur kanak-kanak terbimbing sebaliknya membawa satu konsep yang bermakna (Shahbuddin Hashim \& Noor Miza Abdul Rahman, 2014).

Pendefinisian yang sempit menjelaskan baka dan genetik mempengaruhi $I Q$ sukar untuk diubah melalui pengalaman seseorang. Malahan, turut dinyatakan bahawa masa depan seseorang telah ditakdirkan oleh kecenderungan semulajadi ini (Mohd Azhar Abd. Hamid, 2005). Kehebatan dan keunikan animasi kartun yang mempersonakan telah menarik perhatian kanak-kanak untuk menjadikan rancangan kartun tontonan sebagai model ikutan. Kasih sayang si anak tanpa disedari oleh ibu bapa melalui tontonan rancangan kartun menarik tanpa mengira masa. Sejajar dengan kepimpinanan watak dalam tontonan, kanak-kanak menggunakan daya $I Q$ mereka untuk bertindak mengikut kemampuan, tahap umur dan kesediaan mereka dalam mempelajari sesuatu. Pandangan A. Aziz Deraman (2005) menjelaskan, "masyarakat yang dibiarkan berubah tanpa pengarahan dan kepekaan kepimpinan lambat laun akan keliru tanpa arah" (hlm.144). Oleh itu, kajian ini akan memfokuskan kepada Pengurusan daya intelek kanak-kanak melalui rangsangan imaginasi dalam animasi Upin dan Ipin episod Cari dan Simpan berdasarkan Prinsip Kepimpinan.

\section{PERMASALAHAN}

Perkembangan intelek kanak-kanak bermula dengan kelangsungan hubungan erat antara anak-anak, orang dewasa dan persekitaran. Sebagai orang dewasa khususnya ibu bapa, bimbingan mereka terhadap anakanak adalah berbeza. Paksaan dalam membimbing dikhuatiri hanya akan meninggalkan impak buruk kepada emosi kanak-kanak. Hal ini demikian kerana proses membesarkan anak adalah satu proses pembelajaran dan pengalaman sekali seumur hidup. Perwatakan dewasa yang optimis dilihat berupaya membantu kanakkanak dalam menguruskan intelek dan merangsang imaginasi mereka.

Berdepan dengan perkembangan pesat dalam industri teknologi moden menjadikan animasi kartun sebagai satu medium yang dipercayai umum sebagai medium paling berpengaruh kepada kanak-kanak. Animasi 
kartun bukan hanya menawarkan hiburan kepada kanak-kanak malahan menjadi laluan mereka untuk mengisi masa lapang dalam menjalani kelangsungan hidup. Merujuk Mahmood Nazar Mohamed (dalam kajian Arbaie Sujud dan Nik Rafidah, 2001), menguruskan kehidupan secara bersendirian kanak-kanak dalam proses pembelajaran memerlukan bimbingan orang dewasa terutama dalam konteks di samping mempelajari, mengetahui dan mengenali dunia di sekeliling mereka melalui pengalaman singkat yang perlu dibimbing dengan bijaksana. Dipercayai juga, alam pendidikan awal kanak-kanak juga turut memperlihatkan sifat semulajadi kanak-kanak yang gemar melakukan peniruan melalui pemerhatian dan mudah dipengaruhi.

Sehubungan dengan itu, animasi kartun yang ditonton oleh kanak-kanak seharusnya membawa makna kehidupan secara tidak langsung. Melaluinya, kanak-kanak berupaya menimba pengalaman baru dalam mengenali alam nyata melalui alam maya. Kanak-kanak bagi Ahmad Esa et al. (2007) "mereka terpaksa mengambil masa yang lama untuk menganalisis dan menyelesaikan sesuatu masalah dengan menggunakan daya pemikiran" (hlm.8). Tanpa pimpinan, pengurusan intelek kanak-kanak tidak akan berkembang dan kekreatifan intelek dan kelangsungan imaginasi mereka akan terbiar kaku dengan adanya kekuasaan media. Oleh hal yang demikian, tontonan animasi kartun tanpa kawalan orang dewasa cuba diangkat sebagai satu bahan moden yang pada tanggapan awal dilihat berupaya menguruskan intelek dan imaginasi kanak-kanak sepertimana pengaruh penggunaan bahan bacaan seperti yang terkandung dalam kajian Arbaie Sujud dan Nik Rafidah (2001) menerusi penampakan intelek kanak-kanak.

Hal ini turut melihat kepada kajian Wan Anita dan Azizah Hamzah (2013) yang membuktikan bahawa kebanyakan ibu bapa pada masa kini tidak mempunyai masa yang banyak untuk menjadi 'teman atau pengasuh' kepada penerokaan alam nyata anak-anak. Pandangan terdahulu Warren (dalam Zulzaidi Mahmud, 2008) turut mencadangkan kepada ibu bapa untuk menemani anak-anak ketika menonton televisyen memandangkan kanak-kanak sukar untuk membezakan perkara baik dan buruk. Bahkan, adanya kawalan ibu bapa dalam tontonan rancangan pula dapat memberi manfaat sebagai agen pembudayaan positif tingkah laku kanak-kanak. Secara khususnya, penontonan dan penglibatan aktif watak dewasa dalam cerita berupaya menggantikan watak ibu bapa dalam persekitaran alam nyata amat penting dalam mempengaruhi keberkesanan mesej yang cuba disampaikan oleh media. Malah, keterlibatan watak-watak dewasa dalam cerita berupaya mengubah sikap ingin tahu kanak-kanak menjadi satu amalan dalam kehidupan.

\section{OBJEKTIF}

Kajian ini dilaksanakan adalah untuk mencapai objektif bagi menganalisis bagaimana kanak-kanak menguruskan daya intelek dan imaginasi menerusi keupayaan kepimpinan watak dalam alam maya untuk mengubah sikap negatif kanak-kanak menjadi amalan positif dalam pengurusan kehidupan seharian. Bagi mencapai objektif kajian ini, pengkaji menggunakan salah satu daripada lima prinsip yang terkandung dalam Pendekatan pengurusan, iaitu Prinsip kepimpanan.

\section{METODOLOGI}

Secara umumnya, penyelidikan ini dijalankan dengan menggunakan kaedah kualitatif. Kajian ini dilakukan dengan berpandukan dua kaedah utama iaitu kaedah kepustakaan dan kaedah analisis teks. Pengumpulan data dirujuk melalui kaedah kepustakaan melalui bahan seperti buku, jurnal dan tesis. Pengkaji juga telah memanfaatkan penggunaan teknologi maklumat bagi memperoleh sebegitu banyak maklumat seperti jurnal, tesis dan artikel-artikel yang berkenaan melalui pengaplikasian internet. Kaedah analisis transkripsi video ini dilakukan dengan memilih transkrip yang bersesuaian dan melalui proses penontonan video dan pembacaan teliti bagi mengenal pasti struktur yang relevan dan bersesuaian dengan unsur-unsur di bawah 
Prinsip Kepimpinan. Penelitian analisis memberi fokus utama terhadap struktur dalam transkrip iaitu watak dan isu yang diteliti dari segi tindakan dan pemikiran yang terkandung dalam episod Upin dan Ipin (selepas ini menggunakan $U I$ ) pilihan pengkaji.

Kaedah transkripsi video animasi dilakukan melalui proses penyisihan skrip UI yang bersesuaian selepas proses tontonan dan transkripsi. Kajian ini dibataskan dengan mengkaji hanya satu (1) transkrip animasi $U I$ yang menjadi pilihan pengkaji. Pemilihan bahan berbentuk animasi episod UI yang dipilih pengkaji adalah berdasarkan kesesuaiannya dengan teori dan objektif kajian yang dijalankan. Penelitian keseluruhan kandungan transkrip dilihat dari segi strukturnya bersesuaian dan relevan dengan Dimensi Pendidikan yang terdapat dalam Prinsip Kepimpinan berdasarkan Pendekatan Pengurusan. Pendekatan Pengurusan yang diperkenalkan oleh Muhammad Mokhtar Hassan (2013) telah menggariskan lima (5) prinsip sebagai asas pegangan dalam Pendekatan Pengurusan. Namun begitu, kajian ini hanya dibataskan dengan mengaplikasikan hanya satu daripada lima prinsip yang telah diperkenalkan iaitu Prinsip Kepimpinan. Rumusan kajian mendapati bahawa pengkaji berhasil membuktikan wujudnya pengurusan intelek kanakkanak menerusi kepimpinan watak dewasa dalam membimbing kanak-kanak dalam kehidupan alaf ke-21.

Berpegang kepada rumusan awal pengkaji terdahulu, pengkaji mengetengahkan animasi kartun sebagai bahan kajian media yang lebih bersesuaian dengan peredaran zaman kanak-kanak pada masa kini. Melaluinya, pengkaji memperlihatkan keupayaan kepimpinan watak dalam kartun $U I$ dalam menguruskan kehidupan tanpa sedar kanak-kanak. Episod animasi UI yang dipilih adalah menerusi episod Cari dan Simpan (CSm9ep10)

\section{KONSEP PENGURUSAN}

Merujuk Mescon, Albert dan Khedouri (1985), pengurusan adalah suatu proses merancang, mengorganisasi, memimpin dan mengawal kerja-kerja yang dilakukan oleh ahli-ahli dalam sesebuah organisasi bagi mencapai objektif dan sasaran yang telah ditetapkan oleh sesebuah organisasi. Hal ini terbukti melalui penjelasan Sofian Ibrahim (1999) bahawa pengurusan telah dipraktikkan beribu tahun terdahulu dan hanya kebelakangan ini sahaja telah dijadikan sebagai satu disiplin pengetahuan.

Berdasarkan takrifan terdahulu, Mohammad Mokhtar Abu Hassan (2013) merumuskan bahawa pengurusan bermaksud:

...suatu proses atau mekanisme yang dibentuk yang memerlukan perancangan strategik yang kondusif, sistematik dan efisien untuk mencapai objektif dan sasaran sesebuah organisasi. Dalam merealisasikan objektif organisasi, penglibatan dan kerjasama daripada anggota organisasi melalui komunikasi dan interaksi yang berkesan dengan menghindari polemik dan krisis adalah elemen yang penting dan perlu diterapkan untuk mencapai objektif organisasi (hlm. 4).

\section{PENDEKATAN PENGURUSAN}

Pendekatan Pengurusan merupakan satu pendekatan moden yang telah diketengahkan oleh Muhammad Mokhtar Abu Hassan (2013) dalam dunia kritikan sastera di Malaysia. Pendekatan Pengurusan ini masih belum diterokai secara serius oleh para pengkritik tempatan. Hal ini demikian kerana pengurusan merupakan entiti yang dianggap terasing dan terpinggir dalam dunia kesusasteraan. Kemunculannya dijangkakan membawa satu aliran pemikiran baharu dan transformasi dalam dunia kritikan sastera. Penampilan satu pendekatan baharu adalah hasil cetusan idea Profesor Dr. Mohamad Mokhtar Abu Hassan seorang sarjana tempatan dalam bidang kesusasteraan Melayu dari Akademi Pengajian Melayu, Universiti Malaya. 
Pendekatan Pengurusan ini diperkenalkan dalam usaha mencari kaedah terbaharu dalam mempelbagaikan teknik mengkaji dan menganalisis karya sastera tempatan.

Mohammad Mokhtar Abu Hassan (2013), menjelaskan Pendekatan Pengurusan ialah pendekatan yang meneliti karya sastera dengan mengaplikasikan lima prinsip asas pengurusan, iaitu Prinsip Perancangan, Prinsip Kepimpinan, Prinsip Pengorganisasian, Prinsip Penstafan dan Prinsip Pengawalan yang dapat diaplikasikan dalam karya-karya sastera tempatan. Merujuk Mohamad Mokhtar Abu Hassan pendekatan ini mengandungi rumusan dan prinsip-prinsip pengurusan yang boleh diaplikasikan dalam karya atau teks sastera. Penelitian prinsip-prinsip ini disarankan pengaplikasiannya terhadap aspek struktur teks iaitu dari segi watak, perwatakan, nilai, isu, persoalan, latar dan pemikiran.

Secara rangkumnya, Pendekatan Pengurusan dirumuskan sebagai suatu proses atau mekanisme yang dibentuk berlandaskan keperluan perancangan strategik yang kondusif, sistematik dan efisien untuk mencapai objektif dan sasaran dalam sesebuah organisasi. Pengurusan dianggap satu medium dan mekanisme yang dinilai dari perspektif kemampuan dan keupayaan seseorang pemimpin dalam mempengaruhi, menerajui atau mengendalikan sesebuah organisasi kekeluargaan, kemasyarakatan dan kenegaraan. Dalam merealisasikannya, penglibatan dan kerjasama daripada anggota organisasi melalui komunikasi dan interaksi yang berkesan perlu diterapkan untuk mencapai objektif bagi sesebuah organisasi.

\section{PRINSIP KEPIMPINAN DALAM PENDEKATAN PENGURUSAN}

Menekuni pandangan awal Ordway Tead (dalam Soekarso dan Iskandar Tutong, 2015) melihat kepimpinan sebagai aktiviti mempengaruhi orang agar mahu bekerjasama untuk mencapai beberapa tujuan yang mereka inginkan. Dengan demikian, kepimpinan dijelaskan sebagai "proses mempengaruhi aktiviti-aktiviti sekumpulan orang dalam organisasi ke arah penentuan dan pencapaian matlamat organisasi" (hlm. 237). Manakala, kepimpinan dijelaskan oleh pula oleh Catwright dan Zender dan Halpin (dalam Maira Akbal, 2008) sebagai "Tingkah laku yang mempunyai keupayaan mengubah haluan sesebuah organisasi. Kepimpinan perlu memlilih kriteria-kriteria tertentu dalam usaha mencapai objektif organisasi” (hlm.132). Dengan itu, bagi tujuan mereka boleh memimpin orang bawahan agar mengikut kriteria yang dipilih untuk tujuan pembangunan dan kejayaan di samping dapat mempertahankan corak kerja berpasukan yang erat.

Merujuk sudut pandangan yang berbeza, Hersey dan Blanchard (dalam Soekarso dan Iskandar Putong, 2015), kepimpinan adalah proses mempengaruhi kegiatan individu atau kelompok dalam usaha untuk mencapai tujuan dalam situasi tertentu.Prinsip kepimpinan merupakan salah satu daripada lima prinsip di bawah Pendekatan Pengurusan yang telah diketengahkan oleh Muhammad Mokhtar Hassan (2013). Prinsip Kepimpinan yang dibincangkan di bawah Pendekatan Pengurusan menjelaskan persoalan yang menjadi tanggapan masyarakat terhadap aspek pengurusan dalam sesebuah karya sastera Oleh sebab itu, kepimpinan merupakan salah satu prinsip yang penting dan mendasari sesuatu pengurusan yang disifatkan sebagai mempunyai pertalian dan hubungan yang erat dengan pengurusan. Kepimpinan merujuk pandangan Tenas Effendy (2000), “Tidak memerlukan kedudukan atau pangkat” (hlm.1).

\section{ANALISIS DAN PERBINCANGAN}

Konsep kepimpinan meliputi aspek pembelajaran bersama yang saling berkaitan dan bermakna demi mencapai matlamat bertimbal balik dalam komuniti (Lambert, 2010). Dalam mendidik anak-anak, golongan dewasa turut menggunakan pendekatan pengajaran dan pembelajaran sama seperti kanak-kanak yang belajar melalui proses pertanyaan, penyertaan, membina makna dan pengetahuan serta refleksi. Golongan dewasa sebagai pemimpin dalam hidup kanak-kanak perlu sentiasa mendengar pandangan, mencabar 
kepercayaan, dan melibatkan diri dalam penilaian dan membina makna dan pengetahuan melalui refleksi dan dialog.

Lambert (2010) menyebut keupayaan kepimpinan sebagai "penglibatan dalam ruang lingkup yang luas secara mahir dalam tugas kepimpinan" (hlm.4). Pembelajaran kanak-kanak merujuk kepada proses membina kebaikan yang meliputi aktiviti pertanyaan, penyertaan, membina makna dan penegetahuan serta refleksi. Hasil pembelajaran yang positif akan memperlihatkan peningkatan amalan positif dalam kehidupan seharian. Bukan sahaja orang dewasa berupaya memimpin, malahan kanak-kanak juga boleh dipupuk kepimpinannya menerusi pembelajaran kerana kepimpinan merupakan satu bentuk pembelajaran. Tambahan pula, kanak-kanak belajar dari persekitaran alam orang dewasa.

Hal ini demikian kerana semua kanak-kanak selain golongan dewasa mempunyai hak, tanggungjawab dan kebolehan untuk menjadi pemimpin memandangkan kepimpinan dianggap sebagai satu proses pembelajaran. Kebebasan tanpa kawalan daripada ibu bapa terhadap kegiatan anak-anak memerlukan si anak membimbing intelek mereka dengan cara tersendiri. Dunia modenisasi membawa kanak-kanak meneroka kehidupan sejajar dengan perkembangan teknologi multimedia yang menjanjikan potensi besar dalam mengubah cara memperoleh, memproses dan menyesuaikan setiap maklumat yang diterima.

Dengan itu, kehadiran kekuasaan animasi kartun turut mengikut jejak. Animasi kartun dalam kecanggihan teknologi media pula membuka peluang seluas-luasnya kepada kanak-kanak sebagai pemegang kuasa kawalan terbesar dalam menguruskan intelek yang diperoleh hasil dari tontonan. Pengurusan intelek kanakkanak bukan hanya terikat dengan teks semata-mata tetapi lebih meluas. Kedinamikan dan keunikan animasi yang mencuit hati membantu mempercepatkan proses pemahaman dan pengekalan informasi yang lebih panjang dalam ingatan kanak-kanak. Bertepatan dengan pendapat Vaughan (dalam Jamalludin Harun dan Zaidatun Tasir, 2003), "pengguna yang tertarik akan memberi lebih tumpuan pada persembahan isi kandungan atau maklumat yang ingin disampaikan dan seterusnya proses penyampaian maklumat berlaku dengan lebih berkesan" (hlm.29).

Di samping itu, proses pembelajaran menjadi semakin menarik apabila diselang-selikan dengan eleman yang menghiburkan dan kartun mampu memikat hati kanak-kanak ketika menonton. Kehadiran watakwatak yang merangsang intelek kanak-kanak untuk mencari maklumat dan menyelesaikan setiap isu kehidupan, berlaku menerusi konsep didikan dan hiburan alam maya. Dengan cara ini, proses pengurusan intelek menjadi seronok dan menonton bukan lagi dianggap sebagai sesuatu yang membebankan minda kanak-kanak. Berdasarkan prinsip kepimpinan menjelaskan pengurusan kepimpinan mempunyai satu pertalian dan hubungan yang erat dengan pengurusan kehidupan manusia (Mohammad Zuber Ismail, Sara Beden dan Mohammad Mokhtar Hassan, 2015).

Melihat keperluannya, kartun mendidik dan menguruskan intelek kanak-kanak dalam memahami keperibadian sosial dalam konteks yang menghiburkan tanpa adanya kuasa paksaan. Justeru itu, kartun $U I$ pada tanggapan awal dilihat sebagai model yang berupaya menguruskan intelek dan imaginasi kanak-kanak menerusi kepimpinan watak dan dorongan yang tersembunyi. Kewujudan watak dewasa dalam kartun $U I$ dilihat berupaya menguruskan intelek dan imaginasi kanak-kanak untuk bertindak balas berdasarkan pengamatannya dalam pengalaman tontonan. UI model kartun yang bukan sekadar bercerita, namun mengandungi pengalaman yang dapat dikongsi bersama khalayaknya dalam simulasi masa nyata dan alam maya melalui saluran pernyataan keintelektualan kuasa media.

$U I$ tidak dianggap sebagai pengganti kepada hubungan kanak-kanak dengan dunia sebenar tetapi kekuatan watak yang terkandung didalamnya dipercayai dapat memimpin menguruskan intelek kanak-kanak melalui pengalaman alam belajarnya, persekitarannya, dan dorongan pengalaman tontonannya. Tanggapan awal mendapati melalui hasil tontonan kanak-kanak berupaya mengubah sikap negatif dan sikap ingin tahu menjadi amalan yang berguna dalam kehidupan seharian tanpa perlunya penglibatan ibu bapa atau agen 
perantara atau petugas yang lain. Kanak-kanak menjadikan watak dewasa dalam kartun sebagai pengantara bagi mentafsirkan keadaan atau situasi yang dihadapi dalam penontonan untuk dijadikan panduan dalam alam pembelajarannya. Dunia tontonan seolah-olah menjadi guru kepada kanak-kanak dengan memproses secara aktif bahan tontonnya (Perloff, 1997).

Pada peringkat awal perkembangan kanak-kanak, pemerhatian terhadap persekitaran mereka begitu mempengaruhi tingkah laku seharian (Bandura, 1996). Malahan, dalam konteks kanak-kanak secara semula jadinya minda mereka mudah dikawal dan dikuasai. Untuk memainkan peranan yang berkesan, media tontonan perlu dieksploitasi sepenuhnya dan bukannya bertindak hanya sebagai alat perantaraan. Media hiburan haruslah membantu memberi maklumat atau gambaran yang boleh dipercayai mengenai peristiwa yang berlaku di luar persekitaran (A. Aziz Deraman, 2005). Olahan apa yang dilihat dan apa yang didengar menyebabkan kanak-kanak mudah terpengaruh.

Bagi menjayakan diri dalam dunia yang kerap berubah dan berorentasikan teknologi, kanak-kanak perlu cekap dalam pemikiran kritikal, menyelesaikan masalah dan rasa ingin tahu yang menebal. Pemikiran berlaku kerana kewujudan rangsangan semasa keraguan dan timbulnya sesuatu masalah. Tujuan seseorang berfikir pula bertujuan untuk mentafsir rangsangan dengan membuat pertimbangan dan keputusan yang rasional terhadap msalah yang dihadapi. UI adalah penimbulan watak yang berada pada praoperasi konkrit 2 hingga 7 tahun yang berkeupayaan berfikir secara logik tetapi masih terbatas.

Justeru, perbincangan ini selanjutnya meneliti struktur cerita dalam episod UI yang menjadi pilihan pengkaji setelah proses penyisihan dilakukan. Penelitian memfokus kepada Prinsip Kepimpinan yang menggerakkan pengurusan intelek dan imaginasi kanak-kanak melalui keterampilan watak dan isu yang diketengahkan dalam episod pilihan. Keintelektualan dan keimaginasian kanak-kanak dalam kajian ini memfokus kepada tanggapan refleksi berupaya mengubah sikap negatif dan ingin tahu kanak-kanak kepada amalan harian melalui kepimpinan watak dewasa dalam kartun (menggantikan peranan ibu bapa). Selanjutnya, dengan adanya Dimensi Pendidikan ini dapat membantu dan mendorong kanak-kanak untuk bertindak dalam alam nyata. Melalui pemikiran kreatif ini, pengkaji memperlihatkan keupayaan pengurusan intelek yang dipamerkan oleh watak $U I$ dalam menyelesaikan isu yang dibangkitkan dalam episod yang dianalisis di samping penampakan rangsangan imaginasi yang kuat dalam isu kajian.

Jadual 1 Carta Pengurusan Daya Intelek dan Daya Imaginasi Kanak-kanak (Didik).

\begin{tabular}{|c|c|c|c|c|c|c|}
\hline Topik & Pencabar & $\begin{array}{c}\text { Yang } \\
\text { dicabar }\end{array}$ & Matlamat & Cara & $\begin{array}{c}\text { Pencapaian } \\
\text { Matlamat }\end{array}$ & Tindakan \\
\hline \multirow{3}{*}{$\begin{array}{l}\text { Cabaran } \\
\text { dapatkan } \\
\text { wang } \\
\text { RM 1 + } \\
\text { Imaginasi }\end{array}$} & \multirow{3}{*}{ Kak Ros } & \multirow{3}{*}{$\begin{array}{l}\text { Upin } \\
\text { Ipin }\end{array}$} & \multirow{3}{*}{$\begin{array}{c}\text { Dapatkan } \\
\text { wang RM 1 } \\
\text { dalam } \\
\text { tempoh 1 } \\
\text { minggu }\end{array}$} & $\begin{array}{c}\text { Cara 1 } \\
\text { Minta dari Opah } \\
(\mathrm{F} 2 \mathrm{~F})\end{array}$ & GAGAL & $\begin{array}{c}\text { Cara } 1 \text { beralih ke } \\
\text { Cara } 2\end{array}$ \\
\hline & & & & $\begin{array}{c}\text { Cara 2 } \\
\text { Minta dari } \\
\text { Ehsan } \\
\text { (F2F+Ganjaran) }\end{array}$ & BERJAYA & $\begin{array}{c}\text { Siasatan (WD) } \\
\text { Penyoalan dan } \\
\text { Bimbingan }\end{array}$ \\
\hline & & & & $\begin{array}{c}\text { Cara 3 } \\
\text { Tolong Cikgu } \\
\text { (F2F+ } \\
\text { Pengalaman) }\end{array}$ & BERJAYA & Bimbingan (WD) \\
\hline
\end{tabular}




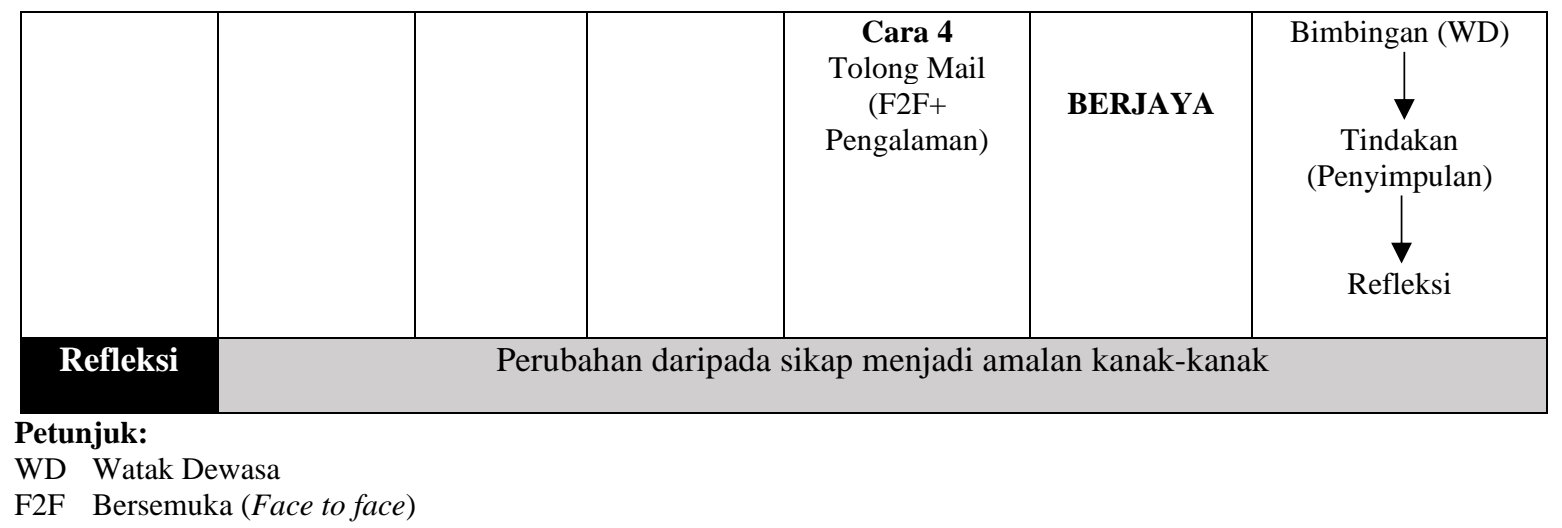

\section{Isu Pencetus dan Cabaran}

Melalui rangsangan imaginasi dan kepimpinan watak dewasa dalam episod penceritaan didapati watak $U I$ berupaya mempamerkan pengurusan intelek kanak-kanak ini. Isu pencetus bermula apabila Kak Ros, kakak kepada watak Upin dan Ipin dengan sengaja telah menimbulkan satu idea kepada UI untuk mendapatkan wang RM 1 seorang dalam tempoh seminggu di samping untuk memerhatikan tindak balas adik-adiknya. Idea ini muncul disebabkan oleh kata-kata adik-adiknya yang begitu mudah mendapatkan dan menghabiskan wang begitu sahaja seperti contoh dialog dalam Jadual 2.

Jadual 2 Perbualan Kak Ros dengan Upin dan Ipin.

\begin{tabular}{|l|l|}
\hline \multicolumn{1}{|c|}{ WATAK } & \multicolumn{1}{c|}{ PETIKAN DIALOG } \\
\hline Upin & Tak susah pun. Tolong atuk dapat singgit. \\
\hline Ipin & Tadi kitorang tolong Tok Dalang bersihkan reban ayam. (semangat) \\
\hline Upin & Lepas tu dia bagi upah. \\
\hline Kak Ros & $\begin{array}{l}\text { Ooooo... kalau rasa senang, akak cabar korang simpan singgit sorang } \\
\text { dalam minggu ni. }\end{array}$ \\
\hline
\end{tabular}

(Dipetik daripada episod CSm9ep10)

Perkembangan dalam pemikiran $U I$ berlaku disebabkan oleh wujudnya rangsangan semasa timbulnya keraguan terhadapa kata-kata Kak Ros yang menggandakan wang yang mereka berjaya peroleh daripada RM 2 kepada RM 4. Pengurusan intelek UI mula melalui suatu proses prosedur yang menyeluruh iaitu merangkumi pengalaman-pengalaman sedia ada dalam ingatan bagi menyelesaikan masalah yang sedang dihadapi tanpa dapat membezakan angan-angan dengan kenyataan (imaginasi).

Merujuk kepada keadaan rangsangan imaginasi UI, kedua-dua kanak-kanak ini sedang menggambarkan situasi mereka di tempat makan menaikkan semangat dua beradik ini untuk mendapatkan wang RM 1 supaya digandakan oleh Kak Ros. Bagi kanak-kanak ini apabila mendapat wang yang banyak mereka boleh makan apa sahaja melebihi upah yang diberi oleh Tok Dalang. Dalam keadaan ini, kanak-kanak hanya dapat menumpukan perhatian kepada satu situasi dalam satu masa tertentu sahaja. Malahan, dalam tempoh ini kanak-kanak tidak berkebolehan untuk membuat perbandingan antara proses atau keadaan yang telah diubah dengan yang asal.

Hal ini dengan jelas dilihat menerusi struktur cerita dalam episod ini. UI berdasarkan pengalaman sedia ada membantu Tok Dalang membersihkan reban ayam dan mendapat upah RM 1 turut menggunakan pengalaman yang sama ketika menolong cikgu mengangkat buku dan meminta upah sedangkan situasi dan keadaan telah berubah. Rujuk Jadual 3. 
Jadual 3 Situasi Pengalaman Asal kepada Perubahan Pengalaman Baharu.

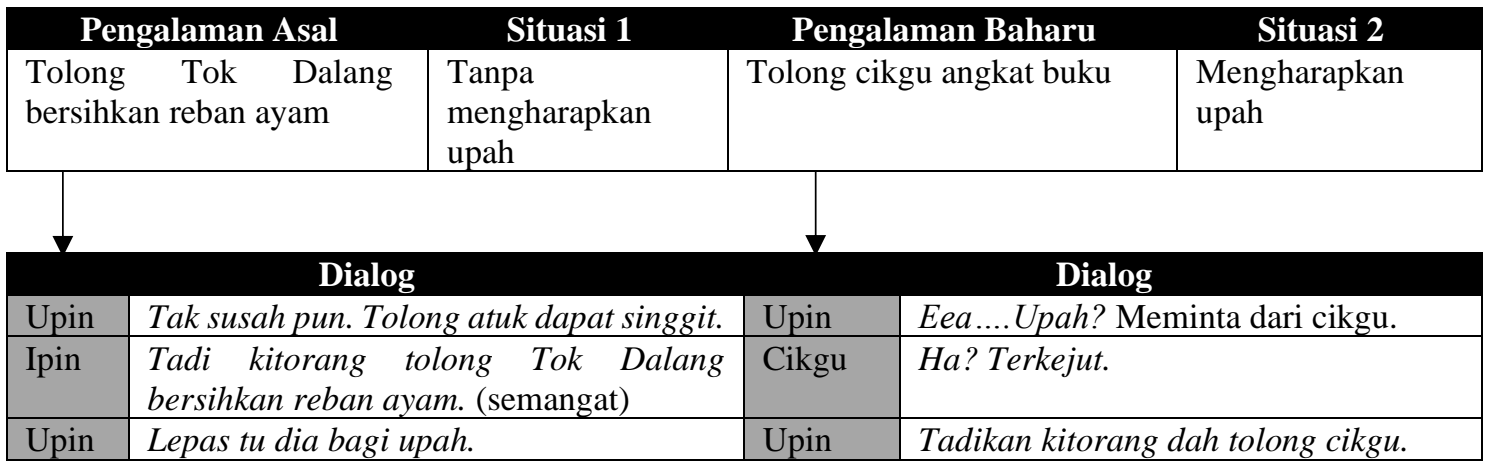

Tanpa pengalaman baharu, pembelajaran baharu dalam diri $U I$ tidak akan berlaku. Hal ini demikian apabila UI menghadapi sesuatu situasi, mereka hanya akan menggunakan pengalaman dan tindakan yang sedia ada dalam menguruskan kehidupannya. Berbeza apabila UI menggunakan struktur kognitif yang sedia ada dalam pengalaman lama untuk diaplikasikan dalam penglaaman baru untuk menghadapi situasi yang dihadapi. Dengan ini, UI berkeupayaan menguruskan inteleknya untuk menyelesaikan masalah yang dihadapi dengan mengubah pengalaman lama kepada pengalan baru berdasarkan situasi yang dihadapi demi untuk memenuhi keperluan. Hal ini jelas dilihat berdasarkan situasi UI menerapkan penglaman lama (tolong atok) ke dalam pengalaman baharu (tolong cikgu) tanpa proses transformasi. Melalui situasi ini, kanakkanak memerlukan bimbingan orang dewasa sebagai perantara bagi menjelaskan betul atau salah sesuatu perbuatan yang dilakukan. Dalam keadaan ini $U I$ diperhatikan tidak mempunyai kebolehan untuk mentafsir perbandingan antara proses dalam pengalaman lama dengan situasi dalam pengalaman baharu. Perhatikan dialog yang berikut:

Jadual 4 Dialog Upin dengan Cikgu Melati.

\begin{tabular}{|l|l|}
\hline \multicolumn{1}{|c|}{ Watak } & \multicolumn{1}{c|}{ Petikan Dialog } \\
\hline Cikgu & Erm...yelah yelah. Lain kali bila nak tolong biar ikhlas. Kan lagi bagus. kan kan? \\
\hline Upin & $\begin{array}{l}\text { Takpelah cikgu, kitorang ikhlas... Sedih dan malu sambil memulangkan semula wang } \\
50 \text { sen tadi kepada cikgu }\end{array}$ \\
\hline Cikgu & Eh, tak apalah, cikgu ikhlas, pergi beli aiskrim. \\
\hline
\end{tabular}

(Dipetik daripada episod CSm9ep10)

Jadual 5 Cara 1.

\begin{tabular}{|l|l|}
\hline \multicolumn{1}{|c|}{ Watak } & \multicolumn{1}{c|}{ Petikan Dialog } \\
\hline Upin & Opah, mintak singgit. \\
\hline Kak Ros & Berselindung, Jangan opah jangan. \\
\hline Opah & Nak buat apa? \\
\hline Upin & Adalah...nanti kitorang bagi balik \\
\hline Opah & Pergi mandi dulu, opah dah x tahan, busuk \\
\hline Upin dan Ipin & Huh... \\
\hline
\end{tabular}

(Dipetik daripada episod CSm9ep10)

Daya intelek $U I$ semakin menyerlah melalui kekreatifan pemikiran mereka berdua melalui cara mereka meminjam wang daripada Ehsan seperti contoh petikan dalam Jadual 6. 
Jadual 6 Cara 2.

\begin{tabular}{|l|l|}
\hline \multicolumn{1}{|c|}{ Watak } & \multicolumn{1}{c|}{ Petikan Dialog } \\
\hline Upin & Ehsan. Engkau ada dua ringgit? \\
\hline Ehsan & Aku ada empat ringgit. Sambil mengeluarkan duitnya. \\
\hline Ipin & Ha, bagusla tu. Boleh pinjam dua ringgit? \\
\hline Ehsan & Eh...tak boleh. Ini duit aku. \\
\hline Upin & $\begin{array}{l}\text { Upin berusaha memujuk Ehsan. Ala bole la ... Esok kitorang bagi } \\
\text { balik. Lepas tu aku belanja ABC. Ha, nak? }\end{array}$ \\
\hline
\end{tabular}

(Dipetik daripada episod CSm9ep10)

Perkembangan intelek $U I$ boleh dilihat sebagaimana kanak-kanak itu menggunakan kebolehan kognitifnya untuk menyesuaikan diri dalam lingkungan persekitarannya. Kepandaiannya menggunakan alat kognitifnya dapat menunjukkan tinggi atau tidak fungsi pemikiran kanak-kanak itu. Hal sedemikian dapat diperhatikan daripada petikan perbualan dalam dialog selanjutnya.

Jadual 7 Cara 3

\begin{tabular}{|l|l|}
\hline \multicolumn{1}{|c|}{ Watak } & \multicolumn{1}{c|}{ Petikan Dialog } \\
\hline Upin & Eea....Upah? Meminta dari cikgu. \\
\hline Cikgu & Ha? Terkejut. \\
\hline Upin & Tadikan kitorang dah tolong cikgu. \\
\hline Cikgu & Erm..yelah yelah. Lain kali bila nak tolong biar ikhlas. Kan lagi bagus. kan kan? \\
\hline Upin & $\begin{array}{l}\text { Tak pelah cikgu, kitorang ikhlas..Sedih dan malu sambil memulangkan semula wang } \\
\text { 50 sen tadi kepada cikgu }\end{array}$ \\
\hline
\end{tabular}

(Dipetik daripada episod CSm9ep10)

IQ Upin berkembang dengan baik apabila melalui pemerhatian 1 yang berlaku ketika dia menolong atuk mencuci reban ayam. Setelah selesai, Tok Dalang memberi upah sebanyak RM1. Ternyata pemerhatian terhadap persekitaran begitu mempengaruhi tingkah laku kanak-kanak. Hasil pemerhatian 1, peniruan cara mendapatkan duit berlaku. Upin menggunakan cara yang sama dengan meminta upah daripada cikgu setelah menolong cikgu mengangkat buku sama seperti pemerhatiannya ketika Tok Dalang memberi upah tetapi pada satu keadaan yang berbeza. Perhatikan perbezaan keadaan yang dinyatakan dalam Jadual 8 .

Jadual 8 Perbezaan Keadaan dan Hasil Upah yang diperoleh.

\begin{tabular}{|l|l|l|}
\hline \multicolumn{1}{|c|}{ Watak } & \multicolumn{1}{|c|}{ Perbezaan Keadaan } & \multicolumn{1}{c|}{ Hasil } \\
\hline Tok Dalang & $\begin{array}{l}\text { Tolong Tok Dalang bersihkan reban ayam- } \\
\text { tidak mengharap upah }\end{array}$ & $\begin{array}{l}\text { Diberi upah kerana kerajinan } \\
\text { Upin dan Ipin }\end{array}$ \\
\hline Cikgu & $\begin{array}{l}\text { Tolong Cikgu mengangkat buku-mengharap } \\
\text { upah }\end{array}$ & $\begin{array}{l}\text { Diberi upah kerana diminta } \\
\text { oleh Upin }\end{array}$ \\
\hline
\end{tabular}

Selanjutnya, Upin berupaya untuk memotivasikan diri dengan terus menggunakan intelek $I Q$ nya berdasarkan pemerhatian isu cikgu melalui kepimpinan watak Mail sebagai penampilan watak kanak-kanak turut mendorong $I Q$ watak $U I$ berusaha mendapatkan wang RM 1 seperti mana yang dicabar oleh Kak Ros. Perhatikan contoh dialog dalam Jadual 9. 
Jadual 9 Cara 4

\begin{tabular}{|l|l|}
\hline \multicolumn{1}{|c|}{ Watak } & Petikan Dialog \\
\hline Upin & Mail kau selalu jual ayam dapat banyak duit ke? \\
\hline Mail & Banyak \\
\hline Upin dan Ipin & Serentak..OOoooo.... \\
\hline Upin & Mail, macamana nak dapat duit? \\
\hline Ipin & Haah, bagitaulah Mail. Mail tersenyum sinis... \\
\hline
\end{tabular}

(Dipetik daripada episod CSm9ep10)

Berdasarkan petikan dalam Jadual 9, menunjukkan UI meminta pendapat Mail cara untuk mendapatkan wang. Dialog serentak UI "Oоoоoo" dengan jelas menunjukkan pengurusan IQ UI terbina kesan dari jawapan dari Mail "banyak". Secara tidak langsung kepimpinan watak Mail membina intelek mendapatkan wang telah berjaya mempengaruhi $I Q U I$ tanpa sengaja. Pengurusan intelek menunjukkan bahawa UI memerlukan dorongan tambahan disebabkan oleh watak $U I$ tidak berada dalam persekitaran gaya hidup berniaga tidak seperti Mail. Hal ini bertepatan dengan perihal pengurusan pemikiran kreatif $U I$ yang memerlukan dua dorongan watak kepimpinan iaitu Mail dan Kak Ros. Kekreatifan intelek UI dilihat daripada usaha mereka untuk menyelesaikan isu mencari idea bagi mendapatkan wang RM1. Pada mulanya kekreatifan intelek UI didorong oleh kepimpinan watak 1 iaitu Mail (yang gemar berniaga).

Namun, setelah mengalami pengalaman yang sukar hanya semata-mata untuk mendapatkan wang RM 1, watak UI tidak mahu lagi berniaga, tetapi kehadiran dorongan watak 2 iaitu Kak Ros memimpin watak UI dalam menguruskan intelek mereka dengan mengajak menjual aiskrim. Perubahan tingkah laku UI yang sudah tidak mahu berniaga dilihat kesan daripada pengalamannya yang menolong Mail berniaga di pasar Malam berdasarkan dialog "Huh...susahnya nak dapat singgit. Mengeluh". Contoh petikan dialog berikutnya turut menunjukkan hasil daripada pengalaman sedia ada mewujudkan pengurusan intelek $U I$. Pada tahap ini $U I$ berada pada tahap memotivasikan diri sendiri demi untuk mencapai kejayaan.Hasilnya, jualan aiskrim $U I$ laris dan mendapat banyak wang seperti mana Kepimpinan watak Kak Ros juga berjaya membantu UI menguruskan intelek mereka bagi isu sukarnya mendapatkan wang seperti dialog dalam contoh yang diberikan dala Jadual 10.

Jadual 10 Dialog Kepimpinan Kak Ros.

\begin{tabular}{|l|l|}
\hline \multicolumn{1}{|c|}{ Watak } & Petikan Dialog \\
\hline Kak Ros & Dah dah...Nah...memberikan adik-adiknya duit seorang RMI \\
\hline Upin & Wahh...dapat duit \\
\hline Kak Ros & Duit ni korang boleh belanja sesuka hati \\
\hline Upin & Hiskh...akak ingat senang ke nak dapat duit? \\
\hline Ipin & Entah akak ni. \\
\hline Upin & Ipin, jomlah kita simpan dalam tabung. \\
\hline (Dipetik daripada episod CSm9ep10)
\end{tabular}

\section{Tindakan (Penyimpulan) Melalui Refleksi}

Refleksi merujuk Lambert, (2010) dijelaskan sebagai panduan mengembangkan dan membangunkan kognitif memikirkan tentang apa yang dilakukan sebelum, semasa dan selepas tindakan. Berikut dijelaskan aliran proses kognitif kanak-kanak berdasarkan Mohd Nazar Mohamed (dalam Arbai'e Sujud, Nik Rafidah Nik Muhammad, Affendi \& Asiah Abdul Rahman, 2001). 
Rangsangan $\longrightarrow$ Persepsi bertukar Keluarkan semula untuk membuat keputusan.

Simpan dalam ingatan

Berdasarkan refleksi yang berlaku menjelaskan $U I$ berupaya menguruskan intelek mereka terhadap isu mencari wang RM 1 setelah dicabar oleh kakaknya. Ringkasnya, pada awal pengurusan intelek UI dibina menerusi kepimpinan watak Mail, tetapi setelah melalui pengalaman yang sukar, memunculkan kepimpinan watak kedua melalui watak Kak Ros yang membina intelek UI setelah kedua-dua kanak-kanak itu berjaya mentransformasikan maklumat berkaitan kesukaran mendapatkan duit melalui dialog dalam Jadual 11.

Jadual 11 Dialog Upin dengan Ipin.

\begin{tabular}{|l|l|}
\hline \multicolumn{1}{|c|}{ Watak } & \multicolumn{1}{c|}{ Petikan Dialog } \\
\hline Upin & Hiskh...akak ingat senang ke nak dapat duit? \\
\hline Ipin & Entah akak ni. \\
\hline
\end{tabular}

(Dipetik daripada episod CSm9ep10)

Watak Kak Ros dan Tok Dalang diberi tanggungjawab dalam membantu kanak-kanak menguruskan intelek kanak-kanak yang menonton. Paparan watak Upin dan Ipin yang menggunakan pemikiran kreatif dan imaginasi dilihat sebagai satu paparan pengurusan yang bijak. Hasil tontonan membuatkan, kanak-kanak dengan mudahnya terurus dengan sendirinya tanpa paksaan daripada mana-mana pihak. Paparan isu UI yang berusaha bersungguh-sungguh untuk mendapatkan wang RM 1 membawa kepada kepimpinan watak model dorongan dan ikutan (Mail) dan watak kepimpinan (Kak Ros) dalam memunculkan kekreatifan intelek kanak-kanak.

Pengurusan intelek kanak-kanak ini kemudiannya diringkaskan menerusi carta alir merujuk Rajah 1.

Berbalik kepada tontonan, khalayak kanak-kanak melalui tontonan isu ini akan terbimbing dengan sendiri dan berupaya menguruskan keintelektualan mereka apabila berhadapan dengan isu sama seperti tontonan dalam alam nyata. Kanak-kanak dapat menguruskan intelek mereka dengan baik bagi mengendalikan isu yang berkaitan. Jika terdahulu kanak-kanak berdasarkan pengalaman sendiri melihat bahawa setiapkali menolong orang akan mendapat ganjaran, namun setelah menonton isu yang diketengahkan dalam episod ini, kanak-kanak yang menonton dapat membezakan pertolongan yang mendapat ganjaran dengan pertolongan yang dilakukan dengan ikhlas hati tanpa mengharapkan ganjaran. Kanak-kanak juga terpimpin melalui pengalaman tontonannya supaya tidak selalu membazir memandangkan sukarnya mendapatkan wang sepertimana yang ditonjolkan oleh watak $U I$.

Ringkasnya, hal-hal yang berkaitan aspek didikan yang diperjelaskan bersesuaian dan bertepatan dengan prinsip kepimpinan yang diketengahkan oleh Mohamad Mokhtar Abu Hassan (2013) di bawah Pendekatan Pengurusan. Berdasarkan pendekatan ini, jelas memperlihatkan bahawa pemimpin memainkan peranan yang penting dalam menguruskan intelek kanak-kanak yang menonton berdasarkan pembinaan intelek yang baik bagi kanak-kanak dan didikan berupaya dibina melalui aspek pengurusan $I Q$ yang berkesan. Tanpa kuasa paksaan watak pemimpin menguruskan intelek kanak-kanak dengan bijaksana menerusi landasan pemikiran yang kreatif. Tiada unsur paksaan dilihat dalam dialog yang dipaparkan. Kanak-kanak diberi kuasa untuk menguruskan keintelektualan mereka sendiri berdasarkan dorongan isu yang dipaparkan. 


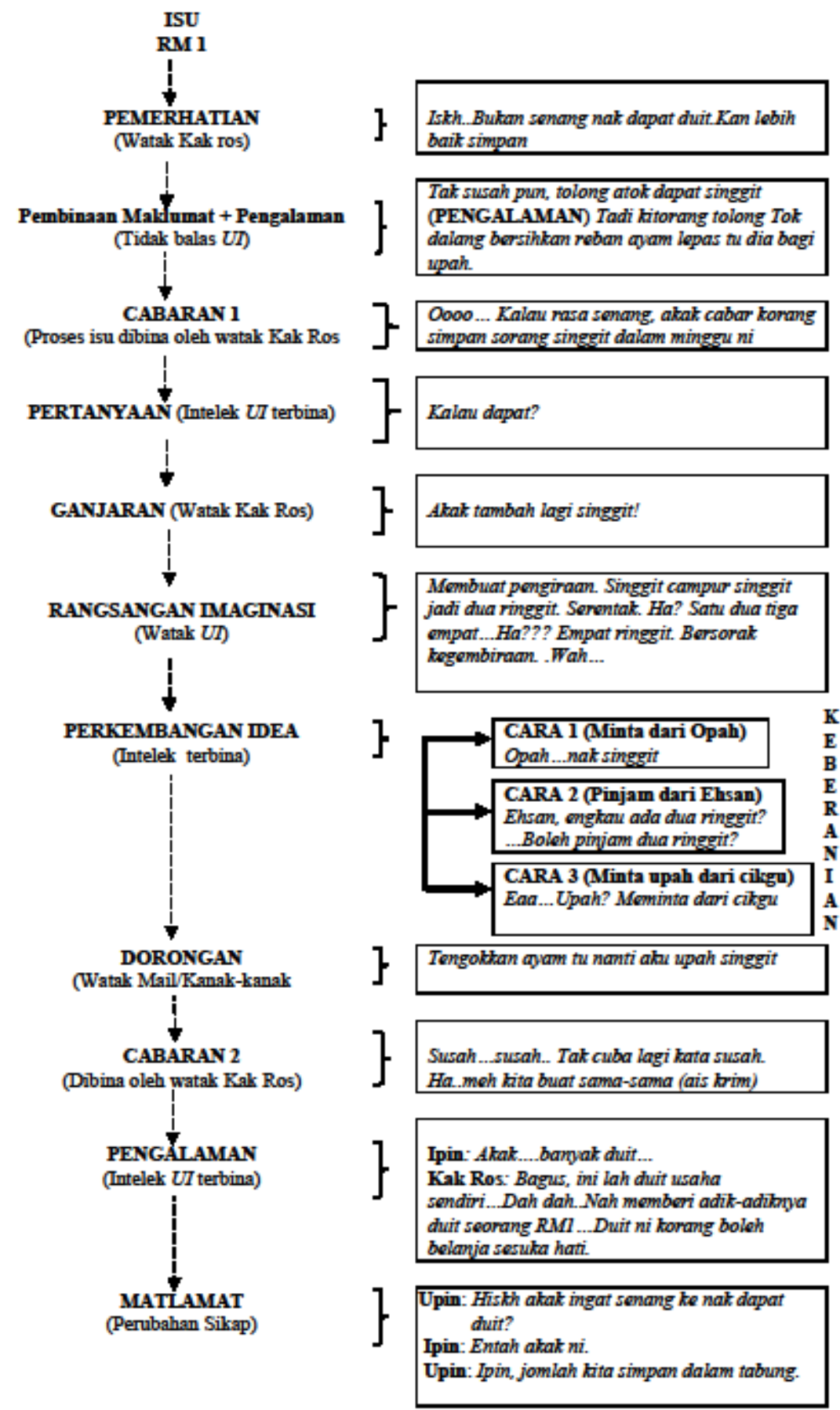

Rajah 1 Pengurusan Intelek UI berdasarkan Rangsangan Imaginasi dan Kepimpinan Watak.

\section{DAPATAN DAN RUMUSAN}

Perubahan baharu dan pengaruh mulitimedia animasi sedikit sebanyak telah membentuk corak intelektual baharu dalam masyarakat khususnya kanak-kanak. Zaman silam mencatatkan, sejarah intelektual Melayu 
tidak pernah mengetepikan pimpinan para ulama, karyawan dan budaya silam dalam mempengaruhi arah pemikiran pimpinannya. Perubahan baharu ini telah mngalihkan pandangan masyarakat dalam menguasai sains teknologi sejajar dengan perkembangan arus kemodenan yang menakluk generasi muda secara khususnya. Lantaran itu, melalui pengurusan intelek yang digarap berlandaskan kepimpinan watak dan isu dalam episod $U I$ pilihan ini amat signifikan khususnya dalam memimpin kanak-kanak menguruskan intelek secara tidak sengaja dan tanpa paksaan. Keintelektualan generasi muda pemangkin negara ini terpimpin inteleknya dengan hanya menonton bahan media yang di dalamnya terkandung kebijaksanaan dan keintelektualan kritis pengarangnya. Pengurusan intelek yang ditanggapi dalam UI menjelaskan manifestasi kepimpinan watak dan isu dalam menguruskan intelek generasi cilik yang kini merentasi zaman dan peradaban. Sehubungan dengan itu, landasan didikan dalam UI sangat relevan dan signifikan dijadikan platform dalam mendorong kanak-kanak menguruskan intelek mereka dengan sendirinya.

Desakan dunia modenisasi mengajak penonton ciliknya menggunakan kebijaksaan meneroka pengalaman sebenar melalui lambakan bahan dalam alam maya yang sama sekali pincang akalnya andai tiada pengurusan yang sempurna. Kanak-kanak pada dasarnya memerlukan pertimbangan-pertimbangan dan refleksi yang logikal terhadap pencarian makna dan penyelesaian terhadap sebarang keraguan dan masalah yang timbul. Berdasarkan perbincangan di atas, jelas menunjukkan bahawa kekuasaan media telah menguasai perjalanan hidup generasi muda ini melalui lambakannya yang tiada batasan. Watak-watak dewasa dalam UI yang diketengahkan dilihat berupaya menguruskan intelek kanak-kanak melalui kebijaksanaan kepimpinan watak dewasa dan ikutan dan dorongan watak kanak-kanak yang dipaparkan dalam penceritaan $U I$. Kebijaksanaan watak memimpin bukan hanya dilihat pada pemaparan watak dewasa tetapi UI turut mengetengahkan watak kanak-kanak dalam bentuk pengawasan yang sewajarnya sepertimana keperluan kanak-kanak yang mendapat bimbingan dan perhatian daripada ibu bapa dalam alam nyata.

\section{RUJUKAN}

A. Aziz Deraman. (2005). Intelektualisme budaya. Kuala Lumpur: Dewan Bahasa dan Budaya.

Ahmad Esa, Baharom Mohamad \& Siti Nasrah Mukhtar. (2007). Peranan multimedia di dalam pembelajaran kanakkanak. Johor Bharu: UTHM.

Arbai'e Sujud, Nik Rafidah Nik Muhammad, Affendi \& Asiah Abdul Rahman. (2001). Sastera Melayu suatu pengantar edisi baharu. Kuala Lumpur: Tinta Press Sdn Bhd.

Bandura, A. (1997). Social learning theory. Amarika: New Jersey.

Jamalludin Harun \& Zaidatun Tasir. (2005). Animasi dari helaian kertas ke skrin digital. Selangor: Ventor Publishing.

Lambert. L, (2010). Keupayaan kepimpinan untuk pembangunan sekolah yang berterusan. (Balasandran A. Raliah, Nor Asikin Salleh dan Junaidah Abdul Jamil, Penterjemah). Kuala Lumpur: Institut Terjemahan Negara Malaysia Berhad dan Institut Aminuddin Baki.

Maira Akbal. Pengaruh animasi dalam perkembangan tutur kata dan pembentukan tingkah laku kanak-kanak. Diperoleh daripada http://www.academia.edu/ 11740185/PENGARUH_ANIMASI_DALAM_PERKEMBANGAN_TUTUR_KATA_DAN_PEMBENTU KKAN_TINGKAH_LAKU_KANAK-KANAK_BAB_1_.

Mescon, M.A. \& Khedouri, F. (1985). Management: Individual and organizational effectivenss. New York: Harper \& Rom.

Mohamad Zuber Ismail, Sara Beden \& Mohamad Mokhtar Hassan. (2015). Hikayat Awang Sulung Merah Muda dari perspektif Pendekatan Pengurusan. Jurnal Pengajian Melayu, 26, 95-116.

Muhammad Mokhtar Abu Hassan. (2013). Pendekatan Pengurusan: Satu metode dalam Kritikan Sastera. Himpunan Ilmuan Sastera Melayu Malaysia Kedua Universiti Pendidikan Sultan Idris, 4-5 Oktober, 2013.

Perloff, R. (1997). Mass media effects. Amarika Syarikat: Universiti Virgin.

Shahbuddin Hashim \& Noor Miza Abdul Rahman. (2014). Pendidikan sosioemosi kanak-kanak. Pahang: PTS Publication \& Distributors.

Soekarso \& Iskandar Putong. (2015). Kepimpinan: Kajian teoritis dan praktis. Putong: Karya Iskandar.

Sofian Ibrahim. (1999). Prinsip Pengurusan. Skudai: Muapakat Jaya Percetakan Sdn. Bhd. 
Tenas Effendy. (2000). Pemimpin dalam ungkapan Melayu. Kuala Lumpur: Dewan Bahasa dan Pustaka.

Wan Anita Wan Abas \& Azizah Hamzah. (2013). Media dalam kehidupan dan perkembangan kanak-kanak. Jurnal Pengajian Media Malaysia, 15(2). 27-39.

Yusliza Yakimir Abd Talib. (2011). EQ asas pembelajaran Tadika Bintang Pintar. Diperoleh daripada http:// www.majalahpama.my/mobile/kanak-kanak/eq-asas-pembelajaran-tadika-bintang-pintar-1.10121.

Zulzaidi Mahmud. (2008). Pengaruh televisyen terhadap minda kanak-kanak. Diperoleh daripada https://zulzaidi.wordpress.com/2008/03/18/pengaruh-televesyen-terhadap-perkembangan-minda-kanakkanak/. 